\title{
Risk factors of infant mortality in Bangladesh
}

\author{
Jyoti Vijay, Kamalesh Kumar Patel ${ }^{*}$ \\ Indian Institute of Health Management Research (IIHMR), Jaipur, 302029, Rajasthan India
}

\section{A R T I C L E I N F O}

\section{Keywords:}

Infant mortality

Socioeconomic and demographic factors

Bangladesh

\begin{abstract}
A B S T R A C T
Background: There exist various studies on the cause and determinants of infant mortality in developing countries. However, to best of our knowledge, none of the studies have seen the effect of institutional delivery and infant's birth size on infant mortality in Bangladesh.

Methods: Data for this study comes from Bangladesh Demographic and Health survey 2014, which is a nationally representative cross-sectional survey. This study uses information on 7,886 infants to analyze the effect of institutional delivery and birth size on infant mortality. Bi-variate and cox regression technique were applied for analyzing the cross-sectional data drawn from representative survey.

Results: Infant mortality was significantly higher in mothers who did not deliver baby at institutions and did not take any antenatal checkups. A significant high infant mortality was found among mothers who belonged to poor wealth status than middle and rich. In addition, infants who had small and very small birth size at the time of delivery had significantly high mortality. The mortality was significantly high in male than female infants. Conclusion: Infant mortality is low among those who delivers baby at institutions, takes antenatal checkups and have higher wealth status. Infants with average birth size and female have less mortality. To reduce the infant mortality in Bangladesh, institutional delivery, antenatal care, baby birth size, child sex and wealth index are important factors. There is urgent need to focus into these factors to reduce infant mortality in the country.
\end{abstract}

\section{Introduction}

Infant mortality rate (the probability of dying between birth and age one) is used as an important indicator to assess the progress of child health. ${ }^{1}$ In Bangladesh, the decline in infant mortality $(87 / 1000$ in 1993 to $38 / 1000$ in 2014) is slower than under 5 mortality rate (133/ 1000 in 1993 to $46 / 1000$ in 2014) in over the last 25 years. ${ }^{2}$ The infant mortality continues to decline from 87 in 1993 to 38 in the year of 2014. As well as neonatal death has significant role in infant mortality. As per Health Bulletin 2017 of DGHS, neonatal mortality is 19 per 1000 live births (SVRS 2016) and 28 per 1000 live births (BDHS 2014). ${ }^{3}$ To achieve sustainable development goals, reduction in infant mortality rate will contribute significantly to improve the health status of children. The country is very far from reaching the objective of Rural Electrification Board to bring down infant mortality by 5/1000 live birth. $^{4}$

In developing countries, a progress has been made to improve child survival and health. However, socioeconomic inequality still same which is a resistant factor of mortality in children. ${ }^{5}$ In recent times, the government attention has been focused to improve the socioeconomic conditions of the households. Mother factors like her education is an important factor which have positive impact on infant mortality. ${ }^{6}$ It ensures the use of primary healthcare services such as immunization and family planning, and better breastfeeding and complementary feeding practices. By taking into consideration these factors, the progress for child health and survival can be achieved. ${ }^{7}$

Various socio-economic and demographic, nutritional and other factors cause infant mortality. Empirical evidence found that reduction in infant mortality is strongly associated with birth size and better health facilities such as full ANC and PNC visits. ${ }^{8}$ The goal of United Nations Sustainable Development cannot be achieved by each country without making an aim of substantial reduction in neonatal mortality to 12 per 1,000 live births and under 5 mortality to as low as 25 per 1,000 live births by the year of $2030 .^{9}$

Around the world, there are several studies which have examined the causes and predictors of infant mortality. In a recent study from Nigeria showed that wealth status is a significant factor for child mortality. The mortality is affected by socio-economic inequality. ${ }^{10}$ However, to the extent of my knowledge, no study has yet examined the effect of wealth and birth size on infant mortality in Bangladesh. ${ }^{11}$ Hence, the present study estimates the infant mortality and effect of wealth status and birth size of baby on infant mortality in Bangladesh.

\footnotetext{
* Corresponding author.

E-mail addresses: vijayjyoti89@gmail.com (J. Vijay), kamaleshkumar.patel@gmail.com (K.K. Patel).
} 


\section{Methodology}

\subsection{Data source}

In this study, the birth file of Bangladesh Demographic and Health Survey 2014 (BDHS-2014) was used. It contains details of 304 infants. The BDHS is the seventh national survey implemented by the National Institute of Population Research and Training, Dhaka. The survey collects information on fertility, childhood mortality, fertility preferences and regulations, maternal and child health, nutritional status of mother and child, and awareness and attitude towards HIV/AIDS. In the country, the households were selected using two stage stratified random sampling. In the first stage, enumeration areas (EAs) were selecting using population proportionate to EAs listed by Census, 2011. In the second stage, 30 households were selected to provide statistically reliable estimates of key demographic and health variables for the country. The target groups were women aged 15-49 years. Those women who were usual resident of the household or stayed in the households on the night before, were eligible to be inter-viewed in the survey. The detailed information can be accessed from the BDLHS, 2014 report. $^{2}$

\subsection{Variables}

In the present study, the variables were categorized as response and predictor variables.

\subsubsection{Dependent variable}

Infant mortality (1q0) is the probability of infant death before the first birthday. It was estimated as the probability of an infant dying before the first birthday.

\subsubsection{Independent variables}

The independent variables were mainly divided into three categories such as mother, child and household related covariates.

Mother-related variables: These variables consist mother education (not educated; educated), occupation (not working; working), age at first birth ( $<18$ and 18 years), institutional delivery (no; yes) and antenatal checkups (no antenatal care; at least one).

Child-related variables: It includes birth order (one; two and above), birth size (average or larger; small or very small) and child sex (male; female).

Household-related variables: The household variables were wealth index (poor; middle; rich), religion (Islam; others) and type of residence (rural; urban).

\subsection{Statistical analysis}

Bivariate and multivariate analysis have been carried out to estimate the association between infant mortality and its covariates. Bivariate analysis performed to estimate the distribution of infant mortality in different groups of predictors. Multivariate analysis such as cox proportional hazard model was used to examine the impact of mother, child and socio-economic factors on survival of infants during first year of life. In this study, cox proportional hazard model was used as it is suitable to analyze the time specific censored observations. ${ }^{12}$

\section{Results}

The estimation of infant mortality by socio-demographic characteristics have been given in Table 1 . The results of the present study found that infant mortality was higher among working mothers in comparison to non-working mothers. Infants of mothers who did not deliver baby at institutions were died more those infants whose mothers delivered baby at institutions. The infants of mothers who did not take any antenatal care were died more than infants of those mothers who
Table 1

Percentage distribution of infant mortality by selected background characteristics in Bangladesh, $2014(N=304)$.

\begin{tabular}{|c|c|c|c|}
\hline \multirow{2}{*}{$\begin{array}{l}\text { Background Characteristics } \\
\text { Mother Factors }\end{array}$} & \multicolumn{3}{|c|}{ Infant Mortality } \\
\hline & $\mathrm{N}$ & $\%$ & $\mathrm{p}$-value \\
\hline \multicolumn{4}{|l|}{ Mother Education } \\
\hline Not Educated & 51 & 3.9 & 0.070 \\
\hline Educated & 253 & 3.7 & \\
\hline \multicolumn{4}{|l|}{ Mother Occupation } \\
\hline Not Working & 212 & 3.6 & 0.461 \\
\hline Working & 92 & 4 & \\
\hline \multicolumn{4}{|l|}{ Age at First Birth } \\
\hline$<18$ years & 184 & 3.8 & 0.584 \\
\hline$>18$ years & 120 & 3.7 & \\
\hline \multicolumn{4}{|l|}{ Institutional Delivery } \\
\hline No & 127 & 4.2 & 0.040 \\
\hline Yes & 177 & 3.5 & \\
\hline \multicolumn{4}{|l|}{ Antenatal Care (ANC) ${ }^{\mathrm{a}}$} \\
\hline No antenatal care & 35 & 3.5 & 0.007 \\
\hline At least one & 82 & 2.2 & \\
\hline \multicolumn{4}{|l|}{ Child Factors } \\
\hline \multicolumn{4}{|l|}{ Birth Order } \\
\hline One & 127 & 4.1 & 0.124 \\
\hline Two and above & 177 & 3.6 & \\
\hline \multicolumn{4}{|l|}{ Birth Size $^{a}$} \\
\hline Average or larger & 139 & 3.5 & 0.054 \\
\hline Small or very small & 42 & 4.3 & \\
\hline \multicolumn{4}{|l|}{ Child Sex } \\
\hline Male & 154 & 3.6 & 0.050 \\
\hline Female & 150 & 3.9 & \\
\hline \multicolumn{4}{|l|}{ Household Factors } \\
\hline \multicolumn{4}{|l|}{ Wealth Index } \\
\hline Poor & 155 & 4.6 & 0.003 \\
\hline Middle & 62 & 4.0 & \\
\hline Rich & 87 & 2.8 & \\
\hline \multicolumn{4}{|l|}{ Religion } \\
\hline Islam & 19 & 3.5 & 0.572 \\
\hline Other & 285 & 3.8 & \\
\hline \multicolumn{4}{|l|}{ Residence } \\
\hline Rural & 233 & 3.9 & 0.462 \\
\hline Urban & 71 & 3.4 & \\
\hline
\end{tabular}

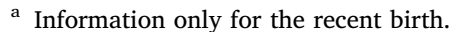

taken at least one antenatal service. As well as, babies born with average or larger birth size were less died in the first year of their life than those infants who born with small or very small size. Infant mortality was higher among poor households followed by middle and rich. It is almost double in poor households in comparison with the rich households. Mortality is slightly higher among illiterate mothers and those mothers who had their first child below 18 years of age. It was higher in female child as compared with the male. Infant mortality was found to be higher among other religious groups as compared with Islam. In urban areas, mortality among infants was slightly less than rural areas.

Table 2 presents the results of cox-regression analysis indicating the relationship between infant mortality and its predictors. There was 1.5 times higher risk of mortality in infants of mothers who gave birth to baby at institutions as compared with those mothers who did not give birth at institutions. It has been revealed that around thirty six percent mortality was less likely to have in those mothers who have availed at least one antenatal care.

A significant relationship was found between birth size and infant mortality as 1.5 times higher risk of mortality in those newborns born with small and very small birth size as compared with their counterparts. Ten percent mortality was less likely to have in female infants than males. An inverse relationship was found between wealth index and infant mortality. Hence, infant mortality was statistically 
Table 2

Result of survival analysis (cox proportional hazard model) of infant mortality by selected background characteristics in Bangladesh, 2014.

\begin{tabular}{|c|c|c|}
\hline Background Characteristics & Odds Ratio & $95.0 \% \mathrm{CI}$ \\
\hline \multicolumn{3}{|l|}{ Mother Factors } \\
\hline \multicolumn{3}{|l|}{ Mother Education } \\
\hline Not Educated ${ }^{\circledast}$ & 1.000 & \\
\hline Educated & 0.744 & $(0.45-1.22)$ \\
\hline \multicolumn{3}{|l|}{ Mother Occupation } \\
\hline Not Working ${ }^{\circledR}$ & 1.000 & \\
\hline Working & 0.997 & $(0.65-1.51)$ \\
\hline \multicolumn{3}{|l|}{ Age at First Birth } \\
\hline$<18$ years $^{\circledast}$ & 1.000 & \\
\hline$>18$ years & 0.986 & $(0.67-1.44)$ \\
\hline \multicolumn{3}{|l|}{ Institutional Delivery } \\
\hline No ${ }^{\oplus}$ & 1.000 & \\
\hline Yes & $1.523 * *$ & $(0.99-2.33)$ \\
\hline \multicolumn{3}{|l|}{ Antenatal Care (ANC) ${ }^{\mathrm{a}}$} \\
\hline No antenatal care ${ }^{\circledast}$ & 1.000 & \\
\hline At least one & $0.641 * *$ & $(0.41-1.00)$ \\
\hline \multicolumn{3}{|l|}{ Child Factors } \\
\hline \multicolumn{3}{|l|}{ Birth Order } \\
\hline $\mathrm{One}^{\circledast}$ & 1.000 & \\
\hline Two and above & 0.929 & $(0.62-1.37)$ \\
\hline \multicolumn{3}{|l|}{ Birth Size } \\
\hline Average or Larger ${ }^{\circledast}$ & 1.000 & \\
\hline Small or Very Small & $1.483^{*}$ & $(0.98-2.24)$ \\
\hline \multicolumn{3}{|l|}{ Child Sex } \\
\hline Male $^{\circledR}$ & 1.000 & \\
\hline Female & $0.908^{* * * *}$ & (1.34-1.95) \\
\hline \multicolumn{3}{|l|}{ Household Factors } \\
\hline \multicolumn{3}{|l|}{ Wealth Index } \\
\hline Poor $^{\circledast}$ & 1.000 & \\
\hline Middle & $0.791 * *$ & $(0.66-0.96)$ \\
\hline Rich & $0.759 * *$ & $(0.46-0.68)$ \\
\hline \multicolumn{3}{|l|}{ Religion } \\
\hline Islam $^{\oplus}$ & 1.000 & \\
\hline Other & 1.011 & $(0.52-1.94)$ \\
\hline \multicolumn{3}{|l|}{ Residence } \\
\hline Rural $^{\oplus}$ & 1.000 & \\
\hline Urban & 0.873 & $(0.56-1.34)$ \\
\hline
\end{tabular}

${ }^{\oplus}$ Reference category, ${ }^{* * *} \mathrm{p}<0.01,{ }^{* *} \mathrm{p}<0.05,{ }^{*} \mathrm{p}<0.10$

a Information only for recent birth.

significantly with institutional delivery, antenatal care, birth size of newborn, child sex and wealth index of the household. A positive relationship was seen between infant mortality and other covariates which were not significantly related with infant mortality.

\section{Discussion}

The present study reported the determinants of infant mortality using data of Bangladesh demographic health survey which is a largescale survey conducted at national level. We have covered socio-economic and socio-demographic factors associated with mortality of infants. The findings of bivariate and multivariate analysis depict that institutional delivery, antenatal care, birth size, child sex and wealth index were statistically significant with infant mortality. A recent study from Bangladesh documented higher neonatal mortality in mothers who never attended school. ${ }^{13}$ Women who had institutional deliveries were more likely to experience infant mortality. ${ }^{14,15}$ High infant mortality was observed in mothers who had not taken any antenatal care than their counterpart. Likely, the same findings were documented by a study from developed country. ${ }^{8}$ More infants born with small size at the time of birth died as comparison to their reference category. Akin to that, recent study from India observed that small birth size is strong determinant for under one mortality. ${ }^{16}$ Similarly, Dancer et al., 2008 supported that low birth weight may increase the risk of dying infants in their first year of life. ${ }^{17}$

Our findings shows that female infants died more than male infants due to the biological advantage against many causes of death in females than males. ${ }^{18,19}$ Poor economic condition of the family leads to high infant mortality due to less utilization of healthcare services during pregnancy and after birth. ${ }^{15,20,21}$ Along with economic conditions, infant mortality was higher in rural women than urban. In this context, a recent study from Bangladesh supports this study findings such as rural respondents experienced higher mortality than urban one. ${ }^{13}$

\section{Conclusion}

The present study has supported that infant mortality more likely depends on socio-economic and demographic characteristics. The findings assist to the policy makers in revising program to achieve sustainable development goals for achieving universal health coverage and childhood mortality. These goals cannot be achieved without substantial reduction in infant mortality. To ensure a significant reduction in infant mortality, attention needs to be paid on nutritional status of mother, socio-economic factors, socio-demographic factors and antenatal care.

\section{Author contributions}

All authors have an equally contributed to prepare the manuscript.

\section{Ethical concern}

The data used in this study is accessible widely in public domain. Hence, there was no need to get ethical clearance.

\section{Conflicts of interest}

Authors declare that they have no conflicts of interest.

\section{Funding source}

This research did not receive any specific grants from funding agencies in the public, commercial, or non-for-profit sectors.

\section{Acknowledgments}

Not Applicable.

\section{Appendix A. Supplementary data}

Supplementary data to this article can be found online at https:// doi.org/10.1016/j.cegh.2019.07.003.

\section{References}

1. Shah MS, Khalique N, Khan Z, Amir A. A community based study of Infant Mortality in rural Aligarh. Australas Med J. 2011;4(1):22-25. Available from: https://www. ncbi.nlm.nih.gov/pmc/articles/PMC3562968/pdf/AMJ-04-22.pdf.

2. National Institute of Population Research and Training. Bangladesh Demographic and Health Survey 2014 [Internet]. Dhaka, Bangladesh. 2016; 2016. Available from: www. mitra.bd.com.

3. Health Bulletin. Government of the People's Republic of Bangladesh, Ministry of Health and Family Welfare, MIS. DGHS; 2017. Available from: http://www.dghs.gov.bd/ index.php/en/home/4364-health-bulletin-2017.

4. WHO. Success factor for women's and child's health: Bangladesh. . Available from: www.who.int; 2015

5. Chowdhury AH, Hanifi SMA, Mia MN, Bhuiya A. Socioeconomic inequalities in under-five mortality in rural Bangladesh: evidence from seven national surveys spreading over 20 years. Int $J$ Equity Health. 2017;16:197. Available from: http:// www.ncbi.nlm.nih.gov/pubmed/29132365.

6. Quansah E, Ohene LA, Norman L, Mireku MO, Karikari TK. Social Factors Influencing Child Health in Ghana. Diemert DJ, editor PLoS One. 2016;11(1):e0145401. Available from: http://dx.plos.org/10.1371/journal.pone.0145401. 
7. Paul VK, Sachdev HS, Mavalankar D, et al. Reproductive health, and child health and nutrition in India: meeting the challenge. Lancet. 2011 Jan 22;377(9762):332-349. Available from: http://www.ncbi.nlm.nih.gov/pubmed/21227494.

8. Gage TB, Fang F, O'neill E, et al. Demogr. 2013;50(2):615-635. Available from: https://www.ncbi.nlm.nih.gov/pmc/articles/PMC3578151/pdf/nihms415424.pdf.

9. World Health Organization (WHO). United Nations Sustainable Development Summit: Sustainable Development Goals [Internet]. New York, USA. 2015; 2015. Available from: https://www.who.int/sdg/en/.

10. Biradar R, Kumar Patel K, Prasad JB. Effect of birth interval and wealth on under-5 child mortality in Nigeria. Clin Epidemiol Glob Heal. 2019;7:234-238. Available from: https://doi.org/10.1016/j.cegh.2018.07.006.

11. Maniruzzaman M, Suri HS, Kumar N, et al. Risk factors of neonatal mortality and child mortality in Bangladesh. $J$ Glob Health [Internet]. 2018 Jun;8(1):010417. Available from: http://www.ncbi.nlm.nih.gov/pubmed/29740501.

12. Adedini SA, Odimegwu C, Imasiku ENS, Ononokpono DN, Ibisomi L. Regional variations in infant and child mortality in Nigeria: a multilevel analysis. $J$ Biosoc Sci. 2015;47(2):165-187. Available from: http://www.ncbi.nlm.nih.gov/pubmed/ 24411023.

13. Roy S, Haque MA. Effect of antenatal care and social well-being on early neonatal mortality in Bangladesh. BMC Pregnancy Childbirth. 2018 Dec 10;18(1):485. Available from: http://www.ncbi.nlm.nih.gov/pubmed/30526513.

14. Bhandari L, Dutta S. Health infrastructure in rural India. India Infrastructure Report 2007: Rural Infrastructure [Internet]. New Delhi: Oxford University Press; 2007:265-271. Available from: http://citeseerx.ist.psu.edu/viewdoc/download? doi $=10 \cdot 1 \cdot 1 \cdot 463 \cdot 4188 \&$ rep $=$ rep $1 \&$ type $=$ pdf

15. Baru R, Acharya A, Acharya S, Kumar S, Nagaraj K. Inequities in access to health services in India: caste, class and region. Econ Polit Wkly. 2010;38:49-58. Available from: http://www.nfhsindia.org/factsheet.html.

16. Kumar Patel K, Gouda J. Infant mortality in northern and southern regions of India: differentials and determinants. Soc Sci Spectr. 2017;3(2):81-92. Available from: https://pdfs.semanticscholar.org/e548/d671e889dfd804b62f6e8a24b8e4682690af. pdf.

17. Dancer D, Rammohan A, Smith MD. Infant mortality and child nutrition in Bangladesh. Health Econ. 2008 Sep 1;17(9). 35-10, Available from: http://doi.wiley. com/10.1002/hec.1379.

18. Alonso V, Fuster V, Luna F. Causes of neonatal mortality in Spain (1975-98): influence of sex, rural-urban residence and age at death. J Biosoc Sci. $2006 \mathrm{Jul}$ 1;38(4):537-551. Available from: https://www.cambridge.org/core/product/ identifier/S0021932005026957/type/journal_article.

19. Sawyer CC. Child mortality estimation: estimating sex differences in childhood mortality since the 1970s. PLOS Med. 2012;9(8):e1001287. Available from: www. plosmedicine.org.

20. Saikia N, Jasilionis D, Faujdar R, Shkolnikov V. Trends in Geographical Mortality Differentials in India [Internet]. Rostock; Germany; 2009; 2009. Available from: https://www.demogr.mpg.de/papers/working/wp-2009-013.pdf.

21. Singh A, Kumar Pathak P, Chauhan RK, Pan W. Infant and Child Mortality in India in the Last Two Decades: A Geospatial Analysis. PLoS One. 2011; 2011e26856. Available from: www.plosone.org. 